\title{
Spatial Equilibrium State and Its Time Evolution of the Multi-functionalization of Regional Land Use in the Eastern China
}

\author{
Li Xin ${ }^{1,2,3}$, Lv Xue ${ }^{2,3}$, Yin Rumeng, ${ }^{2,3}$ Fang Bin ${ }^{2,3 *}$, Jin Tao ${ }^{1}$ \\ ${ }^{1}$ Agricultural College of Yangzhou University, Yangzhou 225009, China \\ ${ }^{2}$ Nanjing Normal University, College of Geography, Nanjing 210023, China \\ ${ }^{3}$ Jiangsu Center for Collaborative Innovation in Geographical Information Resource Development and Application, \\ Nanjing 210023, China
}

Received: 16 April 2020

Accepted: 15 October 2020

\begin{abstract}
In order to revealed the spatial-temporal correlation characteristics and interaction relationship of multifunctional land use in the county of Jiangsu Province, which could provide theoretical support for the spatial planning of the county. This paper constructed multiple functional identification system from three dimensions of production-living-ecological, and quantitatively measures 55 counties' spatial equilibrium state and space-time effect of "production-living-ecological" function in 1996, 2005 and 2015 by means of coupling coordination degree model, Theil coefficient and its decomposition, and LISA time path analysis. The results showed that spatial equilibrium level of multifunctional land use function in the county of Jiangsu Province was relatively low from 1996 to 2015, presenting the spatial characteristics of the overall dispersion and local agglomeration. The coordination degree of multifunctional land use had spatial differentiation characteristics,which were closely related to the stage of social economic development. The time-space transition of multiple functional coordination degree was generally consistent with the cold-hot spot pattern. The regions with relatively long LISA time path were scattered in southern Jiangsu (Nanjing, Suzhou, Wuxi, Changzhou and Yangzhou). The regions with relatively short LISA time path were scattered in northern Jiangsu, central Jiangsu. The multiple functional coordination degree was relatively low in these areas.The county with the largest LISA time path curvature were Zhenjiang, Xinghua, Yancheng, Guanyun etc. Nevertheless, the curvature of LISA time path in most parts of central Jiangsu and northern Jiangsu was generally small. It can be seen that the path locking effect of development of multifunctional land use coordination degree was strong.
\end{abstract}

Keywords: territorial space, land use functions, spatial equilibrium, eastern China

*e-mail: wenyanfang731@163.com 


\section{Introduction}

With the emergence of human beings, land use problems have emerged, and with the development of human society, they have been deepened and broadened [1]. Land use not only affects many natural factors such as air, soil, moisture, terrain, and biology [2], but also affects economic and social human factors [3]. Numerous studies have proven that the carbon cycle, water cycle, atmospheric cycle and habitat change are closely related to land use, issues such as carbon emission, glacial melting, PM2.5, biodiversity weakened etc [4-9]. The relationship between land use and socio-economic transformation and development has also attracted attention in recent years [10-11]. Although land use patterns vary widely around the world, the final result was generally the same: to obtain natural resources for the urgent needs of humanity often comes at the expense of environmental conditions [1]. Therefore, contradictions and conflicts caused by land use have aroused widespread concern of the international community.

When land use is located in a multi-dimensional interface of nature, society, economy and ecology, a multi-dimensional and complex mixed space will be formed [12], and play a considerable role in production-living-ecological function.Spatial scarcity and functional spillovers lead to competition and conflict between different space for seeking maximum benefits [13-14]. From the perspective of practical development, relying on spontaneous forces, it is difficult to achieve both fairness and efficiency when functions are in an unbalanced state [15]. The "convergence effect" in areas with strong functional suitability becomes more apparent, while the "tricklediffusion effect" in backward areas is not significant, economies, populations and industries cluster in local areas. As the "return effect" gradually expands the regional difference, it is difficult to realize the "club convergence" because of the spatial and temporal differences and polarization tendency. However, the spatio-temporal unbalanced distribution of territorial spatial functions can easily induce negative externalities of development and decline of overall efficiency, which is not conducive to the sustainable and coordinated development of the region [16-17]. The multifunction of land use reflects the status and performance of regional land use, which is an important method to evaluate land use [14]. In order to solve the problem of unbalanced spatial and temporal distribution of territorial space functions, China had successively launched the control measures for different functional land (Such as basic farmland, ecological land, urban construction land, main functional areas, etc.) since the 1990s, aiming to reduce the element - function difference of territory space between regions. Nevertheless, macro land use policies cannot adapt to regional development,regional differences, urban and rural issues, and poverty problems still emerge [18-20]. Under the single goal of functional goals, not only the overlapping of regional divisions, but also the regional integration will be hindered [21], which will further aggravate human-land conflicts and regional differences, and it is no longer possible to maintain regional sustainable development. The space equilibrium state of land use functions refers to the game of division of labor among various activities of regional economic activity development, people's life quality and natural ecological protection under the control of key elements of the system, so as to achieve the state of "Pareto benefit" of spatial allocation [22-25]. With the goal of maximizing comprehensive functions, considering benefits and equity, and fully embedding the development concept of human-land harmony and people-oriented, it not only comprehensively evaluated the overall effect of production-living-ecological functions, but also embodied the sustainability of the complex system of land use [14, 17]. Therefore, objective understanding and evaluation of the balance level of the land use functions in territorial space is an important way to scientifically develop territorial space, as well as a demand for new urbanization and "peopleoriented" spatial justice.

In 2015, China's urbanization rate has reached $56.1 \%$, about 1.2 percentage points higher than the world average [26]. Rapid urbanization has greatly promoted China's socio-economic development and improvement in quality of life [27-28]. Nevertheless, China's urbanization has many problems such as population aging, over-exploitation of land, environmental damage, loss of biodiversity, urban and rural issues [29-32]. Land use multi-functionalization (LUMF) is a very significant path to solving the conflicts by coordinating social and economic development [33] and promoting efficient and sustainable land use. Numerous scholars have conducted more in-depth and detailed research on land use multifunctionalization. The research content ranged from single to multiple, covering the connotation of the multiple functions [34-35], the classification system [14, 36-37] and evaluation quantification [38-39], pattern process, spatial optimization [40-42], etc. The scope of the study was mainly national, regional at the macroscale and counties, towns at the micro-scale, and there was still few literature analyzing the multiple functions of county units in the province at the meso-scale. However, the academic research on the coordinated balance of multifunctional land use is still relatively weak at present, mainly focused on the number and spatial structure of land use multi-functionalization [43-44], the mutual transformation of multifunctional land use and their spatial effects [45]. Qualitative understanding of the functional interaction of land use was more than the quantitative expression of the spatial equilibrium degree of the functional interaction of multifunctional land use. Quantitative judgment of the coupling and coordination degree in physics at the critical fluctuations of the disordered or ordered state can effectively determine the equilibrium state of the land use multi-functionalization [46]. In addition, the 
equilibrium state of the multifunctional space is subject to the socio-economic development stage and the law of regional differentiation $[1,33]$, which has significant characteristics of spatial and temporal differentiation. Previous studies focused on the evaluation of the static pattern of land use multi-functionalization, but failed to reveal the law of dynamic evolution, which made it difficult to describe the temporal and spatial change process of the multifunctional land use. This paper attempts to introduce the exploratory time-space data analysis (ESTDA) framework proposed by Rey [4748], which can provide a new idea and method for interpreting this phenomenon and understanding the objective law.

Under the background of rapid industrialization and urbanization, the development pattern of territorial space in China has undergone drastic changes, and the imbalance between urban and rural development and regional development has become increasingly prominent, especially in Jiangsu province. There are great differences in the physical geographical environment, social and economic development in southern Jiangsu, central Jiangsu and northern Jiangsu. Accurately depicting the space-time pattern of the space equilibrium state of land use multi-functionalization in county, it also has great practical value and theoretical significance to rationalize the order of land space development, especially the spatial delimitation of the main functional divisions, and coordinate the sustainable development of regional economy, ecology and environment. In view of this, this paper takes 55 county administrative units in Jiangsu Province as the research object. Firstly, multi-index configuration was used to quantify the equilibrium state of land use multi-functionalization in each county. Secondly, based on Theil coefficient and its decomposition method, the spatial equilibrium state and temporal evolution characteristics of the land use multi-functionalization in the region were analyzed. Then,through spatial exploratory analysis technology and LISA time path, time and space elements were integrated to deeply analyze the functional pattern of land use of the county unit and its temporal changes by means of spatiotemporal coupling.In this way, we re-examine the spatial pattern of economy, population, resources and ecological environment in Jiangsu province, and provide guidance for space development and protection in the future, and also provide reference for the alleviating land use conflict in other countries or regions of the world.

\section{Material and Methods}

\section{The Elements of Land Use Multi-Functionalization}

Land is the spatial carrier, material basis and constituent elements for the construction of beautiful land. It is a complex geographical entity space with multiple functions [49], and meets the needs of human development and utilization through certain land use methods and structures [1]. Based on the ontological thought in philosophy, it is divided into production space, living space and ecological space according to its different utilization modes [14, 17], and then the basic elements and dominant characteristics of each kind of spatial elements are decomposed spatially. Production space mainly refers to the provision of agricultural products, industrial products and service products, and carrying out agricultural production, industrial production and economic development with the help of land bearing capacity [38]. Living space mainly provides the realization of human demand for occupation, residence, transportation, consumption and entertainment [39]. Ecological space mainly provides ecological products and services, and is mainly used to maintain the natural conditions and utility of human survival. Elements and types of territorial space are interlaced with each other. Formally, production space provides material information for living space, and ecological space supports production and living space. Living space is the ultimate meaning and essential requirement of ecology and production space, but the transition boundary between each space is not clear; Functionally, in the process of land use, the land use functions of different regions has the phenomenon of different function intensity and multi-function superposition [12,14], and there is a many-to-many network staggered relationship between elements and functions. In view of the different background environment and the different carrying capacity of resources and environment in different regions, the dominant use of space is also significantly different, which forms the diversified structure and land use multi-functionalization.

\section{The Structure Analysis of Land Use Multi-Functionalization}

Things are universally connected, and each spatial element is arranged and combined in a certain way to form a relative spatial relationship and distribution pattern within a certain geographical range, while the quantity/spatial structure is related to the sustainable and healthy development of the region. Multifunctional land use system is a complex dissipative structure composed of natural system, economic system and social system.It is the product of the interweaving of the bearing capacity of internal resources and environment, the suitability of development and the external environment with obvious quantitative grade and spatial hierarchy.

In different social development stages and regional background environments, the quantitative structure and spatial proportion of the land use function space are significantly different, and the relationship between multiple functions changes dynamically. In the early stage of industrialization, the original ecological space 
was still well preserved and occupied a relatively high proportion. In the meantime, the ecological function took the absolute advantage, while the production and living functions were relatively weak. In the industrialization stage, the rapid expansion of production space and the growth of living space would greatly threaten the ecological function, which would enter the stage of decline; In the post-industrialization stage, the growth rate of production and living space had been limited, and the content had been continuously

Table 1. Evaluation Indicator System of Land Use Multi-Functionalization.

\begin{tabular}{|c|c|c|c|c|}
\hline $\begin{array}{l}\text { Decision } \\
\text { layer }\end{array}$ & Target layer & $\begin{array}{l}\text { Indicator layer } \\
\text { and weight }\end{array}$ & $\begin{array}{l}\text { Indicator description or calcula- } \\
\text { tion method }\end{array}$ & $\begin{array}{l}\text { Indicator meaning } \\
\text { and description }\end{array}$ \\
\hline \multirow{17}{*}{$\begin{array}{l}\text { Compre- } \\
\text { hensive } \\
\text { func- } \\
\text { tions of } \\
\text { production- } \\
\text { living- } \\
\text { ecological }\end{array}$} & \multirow{6}{*}{$\begin{array}{l}\text { Production } \\
\text { Function }\end{array}$} & $\begin{array}{c}\text { Grain yield per unit area } \\
\text { x1 }(0.0662)\end{array}$ & $\begin{array}{l}\text { Grain yield / } \\
\text { Cultivated area }\end{array}$ & $\begin{array}{l}\text { Reflect the stable and increasing } \\
\text { output of grain. }\end{array}$ \\
\hline & & $\begin{array}{l}\text { Land reclamation rate } \\
\text { x2 }(0.0726)\end{array}$ & $\begin{array}{l}\text { Area of cultivated land / Total } \\
\text { area of regional land }\end{array}$ & $\begin{array}{l}\text { Reflect the efficiency of agricultural } \\
\text { production. }\end{array}$ \\
\hline & & $\begin{array}{c}\text { Gross industrial output value } \\
\text { of unit construction land } \\
\text { x3 (0.0590) }\end{array}$ & $\begin{array}{l}\text { Gross industrial output/total area } \\
\text { of construction land }\end{array}$ & $\begin{array}{l}\text { Characterize the efficiency, scale } \\
\text { and level of industrial production. }\end{array}$ \\
\hline & & $\begin{array}{l}\text { Financial contribution rate } \\
\text { x4 }(0.0552)\end{array}$ & $\begin{array}{l}\text { Local general budget income / } \\
\text { Regional total land area }\end{array}$ & $\begin{array}{l}\text { Reflect the economic benefits of } \\
\text { regional land. }\end{array}$ \\
\hline & & $\begin{array}{c}\text { Industrial structure } \\
\text { x5 (0.0576) }\end{array}$ & $\begin{array}{l}\text { Output value of tertiary industry } \\
\text { /GDP }\end{array}$ & $\begin{array}{l}\text { Characterize the trend of economic } \\
\text { development level. }\end{array}$ \\
\hline & & $\begin{array}{l}\text { Economic density } \\
\text { x6 }(0.0626)\end{array}$ & GDP/Regional total land area & $\begin{array}{l}\text { Reflect the concentration degree of } \\
\text { economic development function. }\end{array}$ \\
\hline & \multirow{6}{*}{$\begin{array}{l}\text { Living } \\
\text { Function }\end{array}$} & $\begin{array}{l}\text { Proportion of residential } \\
\text { land in urban villages } \\
\quad x 7(0.0662)\end{array}$ & $\begin{array}{l}\text { Total area of urban and rural } \\
\text { residential land / Regional total } \\
\text { land area }\end{array}$ & $\begin{array}{l}\text { Provide the ability to live and host } \\
\text { populations to meet residential } \\
\text { needs. }\end{array}$ \\
\hline & & $\begin{array}{l}\text { Traffic land density } \mathrm{x} 8 \\
\qquad(0.0716)\end{array}$ & $\begin{array}{l}\text { Total area of land for transporta- } \\
\text { tion / Regional total land area }\end{array}$ & $\begin{array}{l}\text { Reflect the travel convenience of the } \\
\text { evaluation unit, the higher the den- } \\
\text { sity, the more convenient the travel. }\end{array}$ \\
\hline & & $\begin{array}{c}\text { Number of books in public } \\
\text { libraries per capita } \\
\text { x9 }(0.0450)\end{array}$ & $\begin{array}{l}\text { Number of books in public } \\
\text { libraries / Total population }\end{array}$ & $\begin{array}{l}\text { Satisfy the cultural needs of the } \\
\text { people and represent the guarantee } \\
\text { of spiritual life. }\end{array}$ \\
\hline & & $\begin{array}{l}\text { Employment density x10 } \\
(0.0550)\end{array}$ & $\begin{array}{l}\text { Total employed population / } \\
\text { Regional total land area }\end{array}$ & $\begin{array}{l}\text { Solve the people's employment } \\
\text { problem and characterize the total } \\
\text { employment support. }\end{array}$ \\
\hline & & $\begin{array}{c}\text { Hospital beds per } 10,000 \\
\text { people } \\
\text { x11 }(0.0694)\end{array}$ & Hospital beds / Total population & $\begin{array}{l}\text { Reflect the level of medical and } \\
\text { health care. }\end{array}$ \\
\hline & & $\begin{array}{c}\text { Total retail sales of con- } \\
\text { sumer goods per capita x12 } \\
(0.0518)\end{array}$ & $\begin{array}{l}\text { Total retail sales of consumer } \\
\text { goods/total population }\end{array}$ & Reflect consumption level. \\
\hline & \multirow{5}{*}{$\begin{array}{l}\text { Ecological } \\
\text { Function }\end{array}$} & $\begin{array}{c}\text { Agricultural fertilizer input } \\
\text { intensity } \\
\text { x13 }(0.05020)\end{array}$ & $\begin{array}{l}\text { Agricultural fertilizer application } \\
\text { amount/cultivated area }\end{array}$ & $\begin{array}{l}\text { Reflect the negative impact of agri- } \\
\text { cultural ecosystem on the environ- } \\
\text { ment. }\end{array}$ \\
\hline & & $\begin{array}{l}\text { Land degradation index } \\
\text { x14 }(0.0566)\end{array}$ & $\begin{array}{c}\text { Degraded land area / Regional } \\
\text { total land area }\end{array}$ & $\begin{array}{l}\text { Reflect the degree of land degrada- } \\
\text { tion in the evaluation unit. }\end{array}$ \\
\hline & & $\begin{array}{c}\text { Water resources } \\
\text { per capita } \\
\text { x15 }(0.0591)\end{array}$ & $\begin{array}{c}\text { Total water resources / total } \\
\text { population }\end{array}$ & $\begin{array}{l}\text { Evaluate the resource supply func- } \\
\text { tion of the unit. }\end{array}$ \\
\hline & & $\begin{array}{c}\text { Habitat Abundance Index } \\
\text { x16 (0.0492) }\end{array}$ & $\begin{array}{c}\text { The extent of biodiversity in the } \\
\text { region }\end{array}$ & $\begin{array}{l}\text { Reflect the quality of the ecological } \\
\text { environment of the evaluated unit. }\end{array}$ \\
\hline & & $\begin{array}{c}\text { Total Ecological Services } \\
\text { x17 }(0.0492)\end{array}$ & $\begin{array}{c}\text { The total value of regional eco- } \\
\text { logical services }\end{array}$ & $\begin{array}{l}\text { Characterize the ecosystem service } \\
\text { value of the evaluation unit }\end{array}$ \\
\hline
\end{tabular}

Note: The area of degraded land is the total area of saline-alkali land, sand land and bare land. Habitat abundance index $=$ Aibo * $(0.35 *$ forest land $+0.21 *$ grassland $+0.28 *$ water wetland $+0.11 *$ cultivated land $+0.04 *$ construction land $+0.01 *$ unused land) / total area of regional land. The total value of ecological services is calculated by equivalent value method. 
reformed internally, so the efficiency and unit strength of production functions had been continuously enhanced;In the period of quality of life, the proportion of production life ecological space has been relatively balanced, the growth trend of production function is further slowed down, the ecological function is slowly restored, and the life function is greatly improved.

\section{Construction of Evaluation System of Land Use Multi-Functionalization}

The overall benefit of the land use multifunctionalization requires the cooperation of production, living and ecological functions, but their structures and functions of each other are in an unstable equilibrium state. The key elements among their components dominate other elements, and other elements also affect the key elements, while the change of a few key factors will change the overall structure and functions of the land use system [50]. In consideration of sensitivity, integrity and adaptability, 17 key evaluation indicators were selected after eliminating redundant indexes by reviewing literature [35, 38-39] and combining the opinions of three experts in the fields of ecology, geography and land use. To avoid overlapping of indicators and ensure the relevance between indicators and functions as possible, a multifunctional evaluation system had been constructed from three aspects: the efficiency of production functions, the livability of living functions, and the health of ecological functions (Table 1).

The efficiency of production function refers to the relationship between input and output of regional production factors, including agricultural production, industrial production and economic development trend [17], which has a guiding impact on the overall development of the land use multi-functionalization; The livability of living function refers to the ability and service that can be used to guarantee and meet the basic living needs of human beings, including space bearing, employment support, social security and consumption support [14, 39], which plays a key role in the path selection and resource allocation of the overall evolution and development of land use multi-functionalization; The health of ecological function refers to the stability and sustainability of the ecosystem, including the ecological pressure, ecological supply and ecological maintenance of the land [51], which plays a supporting role in the development direction, bearing capacity and suitability of multiple functions.

\section{Study Area}

Jiangsu Province is located between $116^{\circ} 18^{\prime} \sim 121^{\circ} 57^{\prime} \mathrm{E}$ and $30^{\circ} 45^{\prime} \sim 35^{\circ} 20^{\prime} \mathrm{N}$, located in the center of the eastern coastal area of mainland China. It is located in the lower reaches of the Yangtze River and Huaihe River, bordering the East China Sea and the Yellow Sea in the east, adjacent to Anhui Province in the west, Shandong
Province in the north, Zhejiang Province and Shanghai in the southeast. The total land area of Jiangsu Province is $10.26 \times 10^{4} \mathrm{~km}^{2}$, accounting for approximately $1.07 \%$ of the total area of the whole country,it's one of the smallest provinces and autonomous regions in China. Jiangsu Province has developed social economy,but with a high population density (744 persons $/ \mathrm{km}^{2}$ in 2015), heavy land load pressure, rapid expansion of construction land, and facing more prominent humanland contradictions, meanwhile, the gaps in indicators such as its overall economic level, quality of life, the level of the ecological environment are obvious, mainly showing the regional imbalance of high in the south and low in the north. Specifically, the overall development gradient of southern Jiangsu, central Jiangsu, and northern Jiangsu is decreasing, and the degree of industrialization and urbanization in southern Jiangsu is high, which is significantly better than that of central Jiangsu and northern Jiangsu, leading the development of the province. Nevertheless, the development of southern Jiangsu is also facing serious environmental and ecological problems. The per capita arable land is less than $1 \mathrm{mu}$, which is approaching the international warning line of $0.8 \mathrm{mu}$. In recent years, the Taihu Lake has frequent occurrence of blue-green algae, soil heavy metal pollution, acid rain, and smog. Northern Jiangsu has a superior location and rich resources. Its land area and population account for 52\% and $38 \%$ of the province respectively, but the social and economic development lags behind those in southern and central Jiangsu. The agricultural production function of northern Jiangsu is relatively strong but the industrial production function is not competitive, and the regional land space lacks the dominant function, as a result, it is easy to be marginalized in the development process of regional competition and cooperation. Central Jiangsu is striped along the northern bank of the Yangtze River, with socio-economic development between southern and northern Jiangsu. However, the land use function in Central Jiangsu has the phenomenon of homogeneous competition and homogeneous development, which leads to the low quality of land use. (Fig. 1). The socioeconomic development of Jiangsu Province is closely linked to the balanced pattern of multifunctional land use in its territorial space, but the regional differences are significant. Therefore, it is urgent to coordinate the interests of all parties through regional integration to promote comprehensive and sustainable coordinated development.

\section{Data Source and Processing}

The data used in this paper mainly comes from: (1) The socio-economic data comes from the countylevel socio-economic data of Jiangsu Province (19962015) of the "National Geosystems Science Data Sharing Platform-Yangtze River Delta Scientific Data Center"; (2) The data of land use type and area of the research unit were obtained from the summary table 


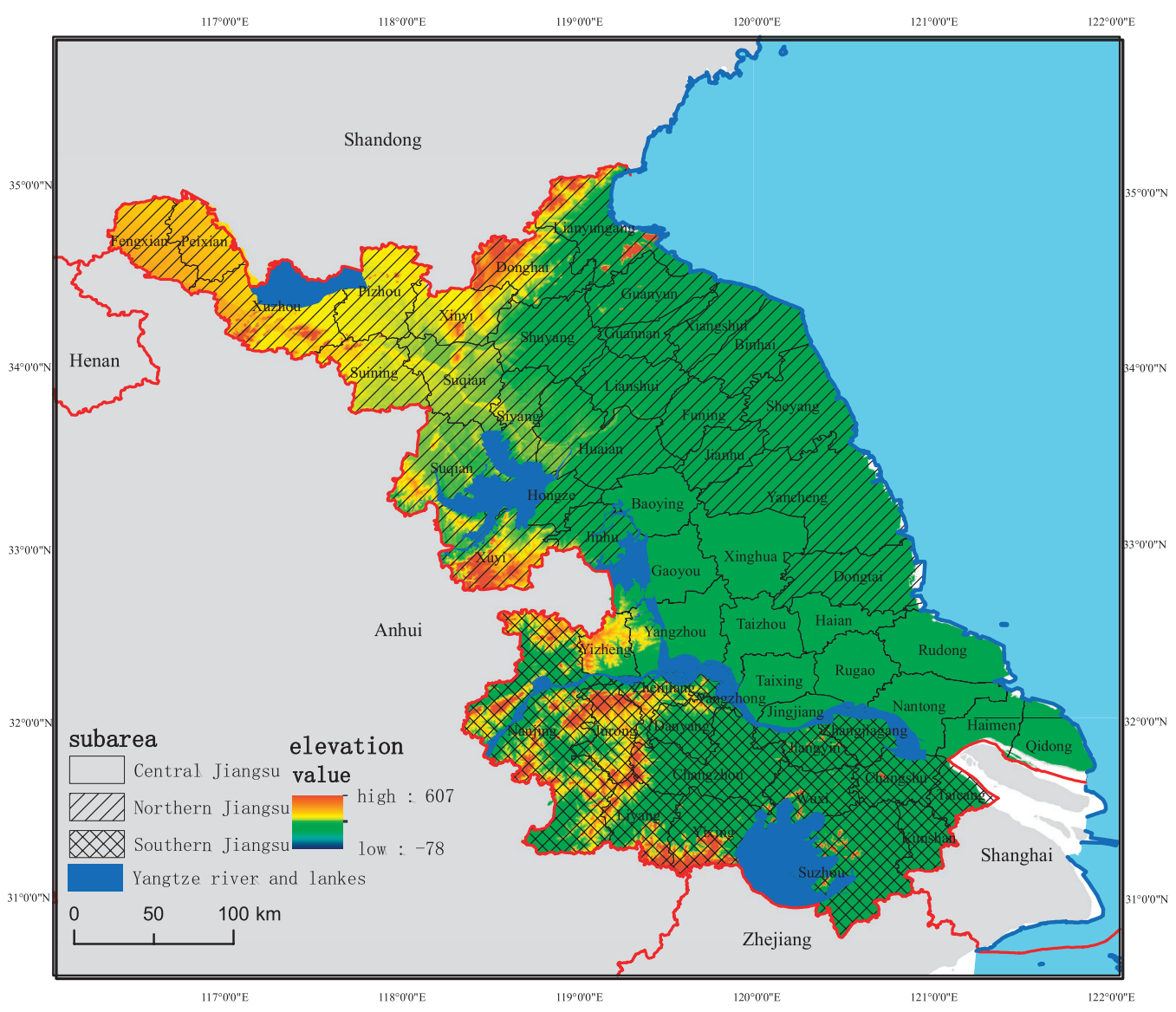

Fig.1 Administrative divisions of Jiangsu Province.

of the second-level (first-level) land change survey conducted by the department of land and resources of Jiangsu province in 1996, 2010 and 2015, with the firstlevel classification divided into 8 categories and the second-level classification divided into 46 categories; (3) The vector data of land use are derived from 1:100,000 maps of land use in Jiangsu Province from the "National Earth System Scientific Data Sharing Platform-Yangtze River Delta Scientific Data Center". In order to maintain the consistency of the research data, 55 county units (Fig. 1) were unified and consolidated according to the adjustment of administrative divisions in 2015 based on the research needs. After the linear transformation of the multifunctional land use evaluation index by the extreme value normalization method, all data are $\in[0,1]$, which meets the experimental requirements, the specific analysis is shown in the literature [52].

\section{Functional Evaluation Model}

The multifunctional index is an important indicator to measure the functional level of land use. The larger the value is, the stronger the function is; otherwise, the weaker $[14,23]$. At present, the evaluation methods mainly included single-factor index method, target weighted average method, principal component analysis method, analytic hierarchy process, matter-element analysis method, approximate ideal value solution, etc. The target weighted average method combined with the index weight evaluation can comprehensively observe the degree and direction of the impact on the multifunctional land use level when a certain index or multiple indexes change. The value of multifunctional land use index in each county refers to the calculation method of Liu Yansui et al. [52], and the formula is as follows:

$$
F_{\mathrm{i}}=\sum W_{j} * Z_{j}
$$

In the formula, $F_{i}$ represents the land use multifunctionalization value of evaluation unit $i$. $Z_{j}$ represents the value of each index, $W$ is the weight, and it's calculated by the mean square deviation decision method.

\section{Interaction Relationship}

\section{Coupling Function}

Referring to the concept of capacity coupling and capacity coupling coefficient model in physics, the coupling degree model of multiple systems (or elements) interaction is generalized, that is: 


$$
C=\left\{\left(u_{1} \cdot u_{2} \cdots \cdot \cdot u_{m}\right) /\left[\prod\left(u_{i}+u_{j}\right)\right]\right\}^{1 / n}
$$

The coupling function of changes between production function, living function and ecological function can be expressed as [53-54]:

$$
C=\left\{\left(u_{1} \cdot u_{2} \cdot u_{3}\right) /\left[\left(u_{1}+u_{2}+u_{3}\right)\left(u_{1}+u_{2}+u_{3}\right)\right]\right\}^{1 / 3}
$$

In the formula, $C$ is the coupling degree of production function, living function and ecological function, $\mathrm{C} \in[0,1], u_{1}, u_{2}, u_{3}$ are the comprehensive index values of production function, living function and ecological function respectively.

\section{Coupling Coordination Model}

The coupling coordination model reflects the coordination status in the interaction coupling process of production function, living function and ecological function, and its calculation formula is as follows:

$$
\begin{gathered}
D=(C \times T)^{1 / 3} \\
T=a \times u_{1}+b \times u_{2}+c \times u_{3}
\end{gathered}
$$

In the formula, $D$ is the coupling coordination degree; $C$ is the coupling degree; $T$ is the comprehensive index of production function, living function and ecological function; $u_{1}, u_{2}, u_{3}$ are the comprehensive development levels of production function, living function and ecological function respectively; $a, b, c$ are undetermined coefficients. Considering the regional characteristics, this paper states that the ecological function, living function and production capacity are equally important, so the three factors are all set to $1 / 3$.

In order to intuitively reflect the degree of coupling and coordination of production functions, living functions and ecological functions, the degree of coupling coordination has been divided. The specific criteria for the division were described in [55].

\section{Theil Coefficient and Its Decomposition}

The measures of spatial disequilibrium mainly include variation coefficient, Gini coefficient, Aikenson index, Shapley value, Theil coefficient, etc. Regional differences were usually decomposed by region or source, and Gini coefficient was relatively common. Scholars usually decomposed it into three parts: intragroup gap, inter-group gap and residual item, but most studies ignored the explanation of residual item, so the expression of influencing factors of regional difference was incomplete [38]. Taking the county area as the basic unit, the Theil coefficient can be used for two-stage nested decomposition, so as to decompose the regional imbalance into inter-regional differences and intraregional differences of south Jiangsu, central Jiangsu and north Jiangsu as well as the overall differences of land use multi-functionalization of the whole province. Considering that the spatial disequilibrium of land use multi-functionalization spatial function index is relative to the area, the larger the Theil coefficient is, the stronger the spatial disequilibrium is [56]. The calculation formula is as follows:

$$
T_{t}=\sum_{i=1}^{n} \frac{y_{i}}{y} \lg \frac{y_{i} / y}{\mathrm{x}_{i} / x}
$$

In the formula, $T_{\mathrm{t}}$ is the overall Theil coefficient, $n$ is the number of study areas, $y_{\mathrm{i}}$ is the spatial equilibrium index of multifunctional land use in the $\mathrm{i}_{\text {th }}$ region; $y$ is the sum of the equilibrium degree of regional land use multi-functionalization, $x_{i}$ is the area of the $\mathrm{i}_{\text {th }}$ region, and $x$ is the total area of the region. The decomposition formula of Theil coefficient is as follows:

Intra-regional spatial disequilibrium degree:

$$
T_{w}=\sum_{k=1}^{k} \frac{y_{i}}{y_{k}}\left(\sum_{i \in \mathrm{g}_{\mathrm{k}}} \lg \frac{y_{i} / y_{k}}{1 / n_{k}}\right)
$$

Inter-regional spatial disequilibrium degree:

$$
T_{z}=\sum_{k=1}^{k} \frac{y_{i}}{y} \lg \frac{y_{i} / y}{n_{k} / n}
$$

In the formula, $\mathrm{n}_{k}$ is the number of county units in the region; $\mathrm{y}_{k}$ is the sum of the multifunctional landuseal equilibrium of each subregion; $\mathrm{k}$ is the number of county-level units in the subregion.

\section{LISA and LISA Time Path}

LISA time path can measure the stability level of LISA coordinates composed of attribute variables and spatial hysteresis in Moran scatter diagram, and explain the spatio-temporal collaborative changes of multifunctional land use in different counties and cities within the region, as well as the spatio-temporal dynamics of local spatial differences and multifunctional land use levels [57]. During the research period, the LISA coordinates of each county unit were composed of the standardized value of multifunctional land use level and the corresponding spatial lag term [47], expressed as $\left.\left[\left(y_{i, 1}, y L_{i, 1}\right),\left(y_{i, 2}, y L_{i, 2}\right), \ldots y_{i, t}, y L_{i, t}\right)\right]$, where $y_{i, t}$ represents the standardized value of multifunctional land use level of region $i$ in year $t ; y L_{i, t}$ represents the lag term of region $i$ in year $t$, its geometric features include path length, curvature and transition direction [47-48]. The length of LISA time path indicates the 
dynamic structure of regional and local space, and the calculation formula is as follows:

$$
N_{i}=\frac{N^{*} \sum_{t=1}^{T-1} d\left(L_{i, t}, L_{i, t+1}\right)}{\sum_{i=1}^{N} \sum_{t=1}^{T-1} d\left(L_{i, t}, L_{i, t+1}\right)}
$$

In the formula, $N$ is the number of space units; $T$ is the length of research time; $\mathrm{d}\left(L_{i, t}, L_{\mathrm{i}, t+1}\right)$ is the moving distance of the space unit $i$ from time $t$ to $t+1$. The larger the value of $N_{\mathrm{i}}$, the more obvious the change of local spatial structure. The curvature of LISA time path indicates the fluctuation of regional spatial structure, the calculation formula is as follows:

$$
D_{i}=\frac{\sum_{t=1}^{T-1} d\left(L_{i, t}, L_{i, t+1}\right)}{d\left(L_{i, t}, L_{i, t+1}\right)}
$$

The larger the value of $D_{i}$, the more tortuous the time-varying characteristics of the local spatial structure, and the worse the spatial stability.

\section{Results and Discussion}

\section{Equilibrium Status of Land Use Multi-Functionalization in Counties of Jiangsu Province}

The target weighted average method was used to measure the value of land use multi-functionalization in counties of Jiangsu Province, and the coupling coordination degree was used to characterize the promoting or restricting environment between the functions, and the spatial equilibrium status of land use multi-functionalization in the region from 1996 to 2015 was obtained (Fig. 2).
From 1996 to 2015, the functional coupling coordination degree of land use multi-functionalization in counties of Jiangsu Province showed a slight downward trend, with the coordination degree ranging from 0.22 to 0.45 . The overall coordination degree was relatively low and had regional differentiation characteristics. Coordination degree of land use multi-functionalization was increasing in the south of Jiangsu, while the coordination degree of land use multi-functionalization was decreasing in most areas of central and northern Jiangsu. Taking 2005 as the segmentation point, it had obviously phased characteristics. From 1996 to 2005, the coupling coordination degree of land use multi-functionalization decreased slightly around the municipal area, with a decline range of 0.0001-0.0607, and the rest areas increased in varying degrees. After 2005, the coupling coordination degree of land use multi-functionalization in central and northern Jiangsu generally declined, while land use multi-functionalization in southern Jiangsu gradually stabilized after the rapid development in the previous stage. In the past 20 years, land use multifunctionalization in counties of Jiangsu province was in the category of mild imblance, moderate imblance, and imminent imblance. Compared with 1996, the number of regions imminent imblance decreased in generally, the number of regions with mild immblance remained stable, and the regions with moderate imblance increased; From 2005 to 2015, the moderate imblance region expanded intensively, the mild immblance region was gradually squeezed and shrunk, and the regions on the verge of imblance were further concentrated in local county units in southern Jiangsu (such as Kun shan,Zhang jia gang and Jiang yin). The above analysis shown that the regional differentiation of multifunctional land use level in each county unit had expanded, especially the regional spatial differentiation had increased significantly during 2005-2015. At this stage, urbanization and industrialization were rapidly promoted, and the tendency of industry-oriented

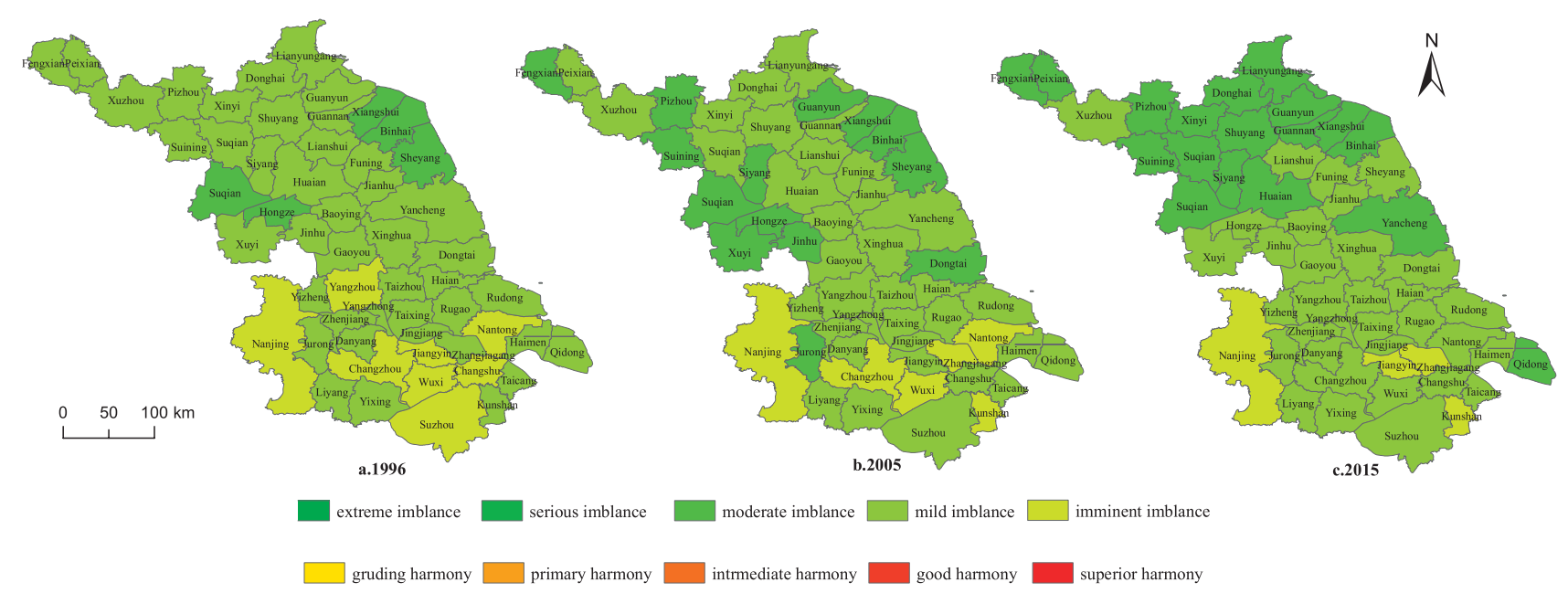

Fig. 2. Spatial pattern of the spatial equilibrium of land use multi-functionalization in counties of Jiangsu Province. 
development was prominent, resulting in the continuous game evolution of the land use multi-functionalization within the region, and the development order was more disordered in the reconstruction [6].

The regions with high coupling coordination degree of land use multi-functionalization in the county area of Jiangsu province were mainly concentrated in the metropolitan area of Nanjing and the economic zone of south Jiangsu, while the mild imblance areas were widespread in the whole region, and the moderate imblance areas were mainly located in the areas around Hongze lake, the coastal area of north Jiangsu and the reclamation area of coal mines. As a whole, the coupling and coordination degree of land use multifunctionalization in Jiangsu Province was obviously "high in the South and low in the north", and the regional differences were prominent, which was due to the reasonable industrial structure, convenient transportation, population agglomeration, urbanrural integration of Suzhou, Wuxi and Changzhou et al, as well as the condition and ability of land use multi-functionalization were relatively coordinated; The low-value areas were mostly located on the north bank of the Yangtze River, especially in the counties in the northeast. The morphology of the low-value areas were mostly clustered in patches. The reason was that the economic development of this region was relatively lagging behind, and it was mainly dominated by agricultural production function, the regional economic density and industrial production function were relatively low, resulting in weak overall production capacity. Moreover, due to the weak radiation-driven capabilities of central cities in these regions, the development of living functions was still not perfect.

The functional coupling coordination degree of land use multi-functionalization in counties of Jiangsu Province had the characteristics of overall decentralization and local agglomeration (Fig. 2). Moderate imblance areas were clustered together, such as Hongze Lake, the coastal areas of Northern Jiangsu and the coal mine reclamation areas. In the process of catching up with southern Jiangsu, the production functions occupied an absolutely dominant position, and the living functions was slowly improving, but the industrial structure was still single, focusing on the development of pollution-consuming industries such as energy and heavy industries. With the further infiltration of low-end industrial transfer in southern Jiangsu in recent years, the regional ecological function had been disturbed and oppressed. In addition, the central cities in northern and central Jiangsu had inadequate functions, insufficient radiation-driven capabilities, unbalanced economic development between urban and rural areas, and low integration. The regional land use multi-functionalization lacked the necessary scale agglomeration benefits. The equilibrium state of the land use multi-functionalization showed a clear "Matthew Effect" convergence pattern in "lowlevel". For high-level coordination regions, the degree of coordination was low, and the phenomenon of regional "polarization-diffusion" had not yet formed. In the future, efforts should be made to coordinate the relationship between economic development, ecological protection, and quality of life. Relying on the territorial space planning and the improvement of the rural human settlement environment, to realize the benign interaction and co-existence of land use multi-functionalization.

\section{Measure and Decomposition of Equilibrium State of Regional Land Use Multi-Functionalization}

Decomposition of "production-living-ecological" function is helpful to identify the reasons for the regional differentiation of spatial disequilibrium, so as to better take differentiated measures and making precise strategies. For this reason, standard deviation and range difference were used to calculate the absolute disequilibrium state of the "production-livingecological" functions in Jiangsu province, and the Theil coefficient and its decomposition method were used to calculate the relative disequilibrium state. The measurement results of the spatial disequilibrium of "production-living-ecological" function level in the whole province and three regions of southern, central and Northern Jiangsu were shown in the following three aspects, as shown in Table 2.

Variation coefficient and standard difference can distinguish the deviation degree of a group of data to the average, reflecting the absolute equilibrium degree of the "production-living-ecological" function of the region. The smaller the value, the more balanced the region. From 1996 to 2015, the standard deviation and variation coefficient of the coupling coordination degree of "production-living-ecological" function in Jiangsu province gradually increased. In 1995, it was the lowest value of the two coefficients (standard deviation 0.0423 and coefficient of variation 0.1262 ), while as time went on, it grew slowly in 2005 (standard deviation 0.0483 and coefficient of variation 0.1490), and reached the maximum value in 2015 (standard deviation 0.0489 and coefficient of variation 0.1537 ), indicating that the "production-living-ecological" function in the county area of the province was in an unbalanced development state.In the process of development, there are also obvious stages. The changes of the two coefficients were relatively stable from 1995 to 2005, while the standard deviation and coefficient of variation increased rapidly from 2005 to 2015 .

Between 1996 and 2015, the Theil coefficient of the "production-living-ecological" functional coupling coordination degree in Jiangsu Province showed an overall upward trend, indicating that regional differences were increasing. The Theil coefficient of the northern Jiangsu increased the most significantly, and the change rate reached $12.03 \%$. The growth rate of Theil coefficient in the southern Jiangsu had also increased greatly, with the change rate reached $7.45 \%$. The Theil coefficient in the central Jiangsu was weakly 
Table 2. The Theil Coefficient and Contribution Rate of County Spatial Equilibrium in Jiangsu Province.

\begin{tabular}{|c|c|c|c|c|c|c|c|c|c|c|c|c|}
\hline \multirow{2}{*}{ Year } & \multicolumn{2}{|c|}{ Jiangsu Province } & \multicolumn{2}{|c|}{ Southern Jiangsu } & \multicolumn{2}{c|}{ Northern Jiangsu } & \multicolumn{2}{c|}{ Cental Jiangsu } & \multicolumn{2}{|c|}{ Intra-group } & \multicolumn{2}{|c|}{ Inter-group } \\
\cline { 2 - 15 } & Theil & $\begin{array}{c}\text { Contri- } \\
\text { bution rate } \\
\%\end{array}$ & Theil & $\begin{array}{c}\text { Contri- } \\
\text { bution rate } \\
\%\end{array}$ & Theil & $\begin{array}{c}\text { Contri- } \\
\text { bution rate } \\
\%\end{array}$ & Theil & $\begin{array}{c}\text { Contri- } \\
\text { bution rate } \\
\%\end{array}$ & Theil & $\begin{array}{c}\text { Contri- } \\
\text { bution rate } \\
\%\end{array}$ & $\begin{array}{c}\text { Theil } \\
\text { Contri- } \\
\text { bution rate } \\
\%\end{array}$ \\
\hline 1996 & 0.0613 & - & 0.1104 & 66.74 & 0.0251 & 15.17 & 0.0299 & 18.09 & 0.0586 & 90.16 & 0.0064 & 9.84 \\
\hline 2005 & 0.0659 & - & 0.1182 & 66.84 & 0.250 & 14.59 & 0.0285 & 16.58 & 0.0621 & 94.57 & 0.0036 & 5.43 \\
\hline 2015 & 0.0686 & - & 0.1186 & 67.32 & 0.0281 & 15.96 & 0.0295 & 16.72 & 0.0606 & 92.30 & 0.0029 & 4.39 \\
\hline Mean & 0.0653 & - & 0.1157 & 67.63 & 0.0261 & 15.24 & 0.0293 & 17.13 & 0.0604 & 92.35 & 0.0043 & 6.55 \\
\hline
\end{tabular}

decreased, with the change rate of $-0.05 \%$. It can be seen that the non-equilibrium change rate of "productionliving-ecological" function in northern Jiangsu was higher than that in southern and central Jiangsu, which was due to the acceleration of regional development speed,but there was a non-synchronization in the regions accelerated in the same period. In the future development process, special attention should be paid to the regional division of labor in northern Jiangsu. In areas where there were similar or competitive industries in a certain space, necessary functional dispersal should be performed and the regional spatial structure should be rationally arranged. By comparing the Theil coefficient of Southern, Northern and central Jiangsu, it was found that from 1996 to 2005, the highest average Theil coefficient of Southern Jiangsu was 0.1157, and the contribution rate reached $67.63 \%$, which was much higher than northern Jiangsu (0.0261) and central Jiangsu (0.0293), their contribution rates were $15.24 \%$ and $17.13 \%$, respectively. In general, the coordination degree of the "production-living-ecological" in Jiangsu province was characterized by spatial differentiation, which was mainly due to the gap between county units in southern Jiangsu, central Jiangsu and northern Jiangsu. The Theil coefficient and contribution rate of southern Jiangsu were highest. The economic development of Suzhou, Wuxi and Changzhou in the eastern part of Southern Jiangsu was good, and the urban-rural integration was high. At the same time, although Jurong, Liyang and Danyang in the west had outstanding ecological functions, the development of production and living functions in these areas were still lagging behind, which were limited to the constraints of main function division and ecological red line.Therefore, the function level of "production-living-ecological" among county units in southern Jiangsu was still quite different; There was not much difference in the level of production and living functions among the county units in northern Jiangsu and central Jiangsu.Therefore, the overall Theil coefficient and contribution rate within the region were also small and not much different, but it also reflected from the side that the relatively homogeneous development pattern in central and northern Jiangsu, which lead to the low priority of regional central cities, and the radiation driving effect on surrounding areas need to be enhanced. Mutual stress and squeeze in the spiral development of "production-living-ecological" functions will produce new effects on the development and evolution of regional space, and regional synergy should be gradually enhanced in the future.

The intra-group Theil coefficient of the "productionliving-ecological" functional coupling coordination degree in the three major region had shown an increasing trend of fluctuations. In the past 20 years, the average Theil coefficient was 0.0604 , the contribution rate was $92.35 \%$, and the change rate was $3.40 \%$. Intergroup coordination degree of the "production-livingecological" function was declining overall. From 1996 to 2015, the average value of the Theil coefficient of the coordination degree of the "production-livingecological" function was 0.0043 , the contribution rate was $6.55 \%$, and the change rate was $-55.94 \%$. On this basis, we initially believe that under the three major patterns of southern Jiangsu, central Jiangsu and northern Jiangsu, the level of equilibrium of the "production-living-ecological" function in Jiangsu Province was mainly influenced by the difference of the county unit within the small area. And it is necessary to pay attention to the intra-group differences in southern Jiangsu, and reducing the intra-group differences will be an important path for the coordinated and balanced development of the "production-living-ecological" function in Jiangsu Province.

\section{Local Spatial Correlation Patterns and Its Dynamic Evolution Process}

In general, the coordination degree of land use multi-functionalization in Jiangsu Province showed obvious local spatial correlation characteristics.In terms of quantity, the high-high concentration areas changed from 11 in 1996 to 9 in 2015, and the low-low concentration areas increased from 7 in 1996 to 9 in 2015 (Fig. 3). It can be seen that the coordination degree of land use multi-functionalization in Jiangsu Province was in a unstable development stage from 1996 to 2015; Spatially, the high-high concentration areas were mainly concentrated in the surrounding areas of Suzhou, Wuxi and Changzhou, while the low- low concentration areas were mainly distributed in counties around Hongze 

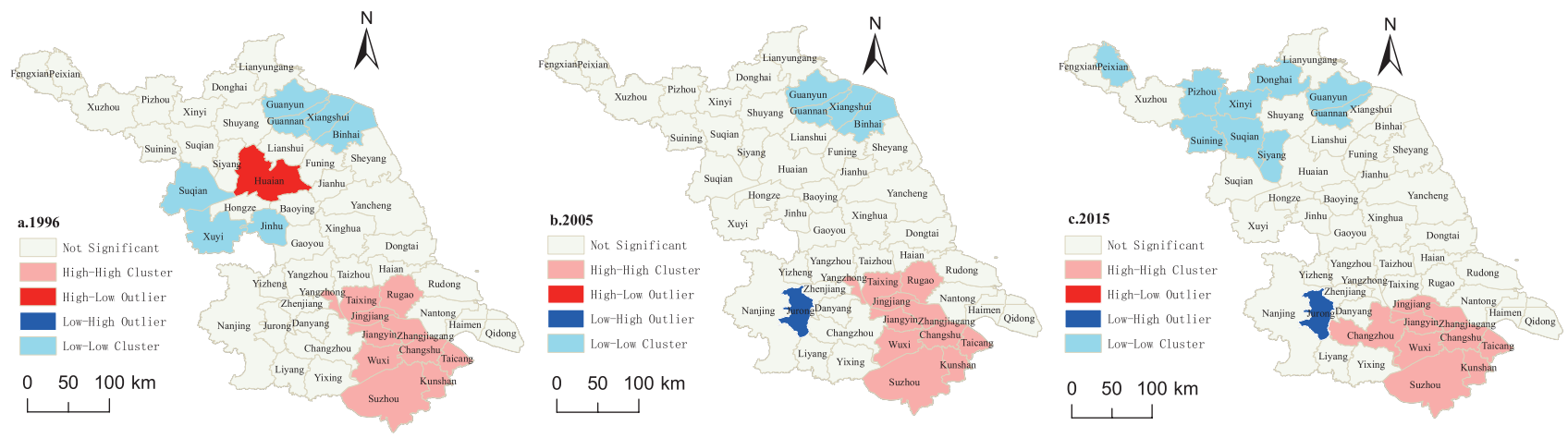

Fig. 3. The spatial pattern of LISA of the land use multi-functionalization in counties of Jiangsu Province.

Lake and the north coast. With the evolution of time sequence, high-high concentration areas were mainly distributed in Suzhou-Wuxi-Changzhou region, while low-low concentration areas were significantly reduced from 7 to 4, and then increased in 2015. In addition, Jurong, an small city near from Nanjing city,where the equilibrium level of the surrounding space was relatively high, showed low-high concentration characteristics, that was, Jurong, which had relatively low coordination degree of land use multi-functionalization, was surrounded by high value areas. In summary,there was a trend of benign resonance in the equilibrium state of the land use multi-functionalization in Jiangsu province, after experiencing the radiation effect of the priority development areas, the degree of equilibrium in northern Jiangsu had increased significantly. In the future, the improvement of coordination degree of land use multi-functionalization and the city primacy of Nanjing and Suzhou-Wuxi-Changzhou region will be conducive to the formation of the "diffusion effect", so as to radiate and drive the equilibrium development of the surrounding areas.

In order to further explore the time sensitivity of spatial equilibrium of the land use multi- functionalization, the LISA time path under the framework of ESTDA (exploratory time-space data analysis) had been used to analyze it in depth from the perspective of spatiotemporal interaction. According to formulas (9) and (10), the spatial geometric characteristics of the LISA time path of each county unit were calculated, and visually expressed by natural fracture method with the help of ArcGIS 10.5 (Fig. 4). The regions with relatively long time path of Lisa were scattered in southern Jiangsu (Nanjing, Suzhou, Wuxi, Changzhou and Yangzhou), which were generally consistent with the pattern of cold hot spots, indicating that the coordination degree of land use multifunctionalization of these regions or their surrounding county units changes more rapidly, which lead to the development of these regions and the evolution of land use multi-functionalization of surrounding counties to a more balanced direction. Nevertheless, the LISA time path in northern Jiangsu, central Jiangsu were relatively short, indicating that the coordination of land use multifunctionalization in these areas was progressing slowly. The counties with the largest curvature of LISA time path were Zhenjiang, Xinghua, Yancheng,Guanyun, which represented the dynamic changes of the multi-
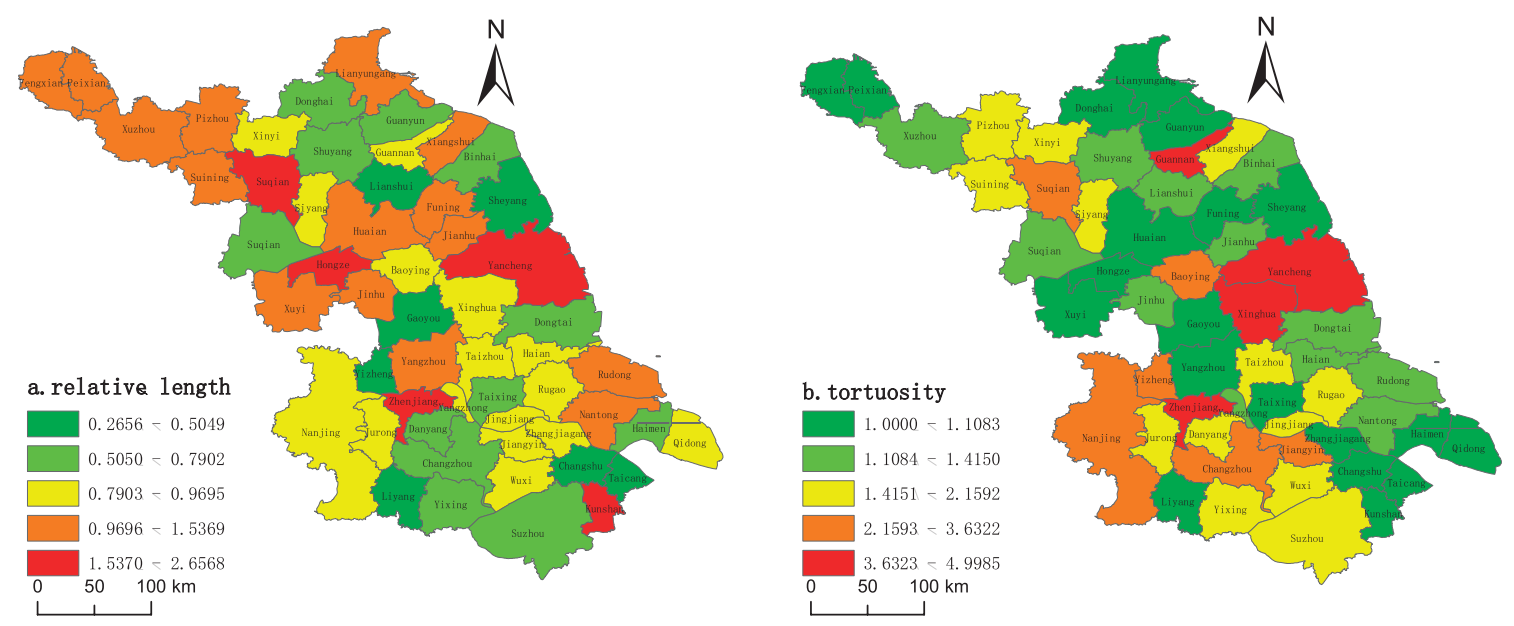

Fig. 4. Spatial distribution of geometrical features of the LISA time path of land use multi-functionalization in counties of Jiangsu Province. 
functionality of land use coordination degree in these regions over time and lack the power to continuously maintain the coordination degree (i.e., lack of growth pole to maintain the balanced development of the region), the curvature of LISA time path in most parts of central Jiangsu and northern Jiangsu was generally small, indicating that the development of coordination degree of land use multi-functionalization had relatively stable spatial dependence and spatial variation direction, that was, the path locking effect was strong. In general, the overall curvature of Lisa was small, and the spatial distribution showed the pattern characteristics of highlow staggered and local agglomeration.

\section{Discussion}

To explore the spatial equilibrium relationship among the three leading functions of territorial space production, living and ecology is the key for Jiangsu Province to realize the spatial coordination and optimization of multifunctional land use,rationalize the order of spatial development, coordinate urban-rural relations, improve regional competitiveness, and realize rural revitalization. In this paper, the theory of manland relationship and the multifunctional theory of land use were used to guide the spatial planning practice, and the development state of production function, living function and ecological function in multi-dimensional space in 1996, 2005 and 2015 was calculated by coupling coordination degree and time-space transition analysis, and the law of time-space evolution has been revealed. Then, the spatial equilibrium state and timespace transition characteristics of land use multifunctionalization in county units were discussed by combining GIS spatial analysis and Lisa time path analysis, which provide a new perspective to clarify the interaction relationship between the land use multifunctionalization. In addition, integrating the multiple attributes of geographic space into the theoretical practice of spatial planning is a useful discussion of the social and material nature of the concept of space from the perspective of the relationship between man and land, and it is also a powerful promotion of the coordination of the "habitation environment".

The results showed that the spatial equilibrium state of the land use multi-functionalization in Jiangsu Province has obvious spatial-temporal differentiation characteristics, and the spatial equilibrium state decreases weakly with the change of time in the early stage of development. The conclusions are slightly different from the previous research results of the land use multi-functionalization in Chongqing and the middle reaches of the Yangtze River [46-56], most of them think that the level of coordination of the land use multi-functionalization in the region has generally risen, and that the development disequilibrium between regions is gradually shrinking. The reason is mainly related to the characteristics of the regional environment and the stage of social and economic development. The above areas are mountainous areas in the central and western regions, with a better background ecological environment, but there is an urgent need to improve the production and living function, the land use multi-functionalization of the region will be more coordinated in the development process. As the core area of the Yangtze River Delta, Jiangsu province has a relatively good stage of social development. The rapid development of production and living functions requires a large amount of space and threatens the ecological function.

As a complex and open system, the spatial and temporal evolution process of land use multifunctionalization is influenced by multiple factors such as the natural environment, politics, economy and society. Existing studies have selected multidimensional indicators such as the value of ecological services, commuting conditions, industrial structure, urbanization level, and population agglomeration effects for analysis [38-39, 52]. In general, the differences and path patterns in the spatio-temporal evolution of land use multi-functionalization depend on the competition and cooperation among the four factors: the regional economic development level, the living bearing capacity, the production factor endowment conditions and the ecological environment. The rule of regional differentiation and the stage of social and economic development dominate the evolution process of land use multi-functionalization. The production function is generally driven by the core of regional economic development level. The better the regional economic development level is, the stronger economies of scale effect will be. Population concentration brings a large number of labor force to the production function, and more jobs need to be provided, so the production function co-exists with it in a virtuous circle. As the support of the production function, once the ecological function is stressed, it will lead to ecological environmental damage and resource shortage, which will aggravate the contradiction between man and land. Living function is driven by composite factors. The convenience of transportation brings the effect of space-time compression, the characteristics of spatial clustering are significant. The convenience of transportation is accompanied by economic and social development, which can further bring more employment opportunities and convenience Public service facilities, the psychological demands of the people to live and work in peace also tend to this; The natural ecological environment affects human survival and health, and a good ecological environment is the guarantee of living functions. Benefit from the accessible transportation network and the friendly ecological and employment environment, living function and production function may overlap in space. Ecological function is influenced by the internal engine of ecological factors and external promotion of life load. Although human activities may damage the ecological environment, the overall scale effect of ecological function is also strong.In addition, 
due to the dynamic and non-linearity of the relationship of land use multi-functionalization, not only the spatial relevance of the mutual functions need to be paid attention to, but also the sequential effect of the future production-living-ecological spatial combination.

Limited to data acquisition and technology reasons, this paper mainly analyzes the interactive stress relationship of production-living-ecological function of land-use, and the specific classification of landuse functions has yet to be refined, and the complex relationships between indicators need to be further explored. The research on the mutual transformation, synergy, and trade-off of space-time effect and its mechanism of multi-functionality of land use needs to be further improved.

\section{Conclusions}

This paper quantifies and evaluates the function of multi-functionality of land use in county units of Jiangsu Province, explores the spatial correlation characteristics and development mode of multifunctionality of land use, and the following conclusions has been obtained:

From 1996 to 2015, the coupling coordination degree of land use multi-functionalization of county units in Jiangsu Province showed a weak downward trend in general, and the overall coordination degree was low with obvious stage characteristics, especially the regional spatial differentiation increased significantly from 2005 to 2015 . Spatially, the coupling coordination degree of land use multi-functionalization at the counties in Jiangsu province presents an obvious spatial pattern of "high in the south, low in the north", with prominent regional differences. The coupling coordination degree of land use multi-functionalization in Suzhou, Wuxi, Changzhou was slightly higher, and the low value areas were mostly located in the north bank of the Yangtze River, which were mostly agglomerated patches in shape. At present, the rapid progress of urbanization and industrialization in Jiangsu province has led to the prominent tendency of industrydriven development, resulting in the continuous game evolution of land use multi-functionalization within the region, and the development order is relatively disordered in the reconstruction. In the future, efforts should be made to coordinate the relationship between economic development, ecological protection and quality of life, and realize the positive interaction and coordination by relying on territory development plan and renovation of rural residential environment to achieve positive interactions and synergies of land use multi-functionalization.

From 1996 to 2015, the coordination degree of land use multi-functionalization in Jiangsu province was still in a state of disequilibrium development, and the differences in the coordination degree of land use multifunctionalization within the region were continuously expanding. Theil coefficient and its decomposition results showed that the contribution rate of intragroup gap keeps increasing, and the equilibrium level of multifunctional land use in Jiangsu province was mainly affected by the differences of county units within the three major regions, especially the intragroup differences in southern Jiangsu.Narrowing the differences within the group will be an important measure for multifunctional land use of Jiangsu Province to move towards a coordinated and balanced development.

The local spatial correlation pattern of land use multifunctionalization coordination degree of the county unit was relatively stable over time. In terms of quantity, the high-high concentration areas changed from 11 in 1996 to 9 in 2015, and the low-low concentration areas increased from 7 in 1996 to 9 in 2015; spatially, the high-high concentration areas were mainly clustered in the surrounding areas of Suzhou, Wuxi and Changzhou, the low-low concentration areas were mainly scattered in some counties around Hongze lake and the northern coastal areas. In the future, it will be still necessary to rely on the coordinated development radiation of Suzhou, Wuxi, and Changzhou Economic Zone to drive other areas to gradually develop into regional coordinated development. In the meantime, it is also necessary to pay attention to the ecological function of the ecological protection area not to be squeezed by the development of production function and living function of other regions.

The regions with relatively long time path of Lisa in county unit were scattered in southern Jiangsu (Nanjing, Suzhou, Wuxi, Changzhou and Yangzhou), which are generally consistent with the pattern of cold hot spots, and the LISA time path in northern Jiangsu, central Jiangsu were relatively short. The counties with the largest curvature of LISA time path were Zhenjiang, Xinghua, Yancheng, Guanyun, which represented the dynamic changes of the coordination degree of land use multi-functionalization in these regions over time and lack the power to continuously maintain the coordination degree (i.e., lack of growth pole to maintain the balanced development of the region). The curvature of LISA time path in most parts of central Jiangsu and northern Jiangsu was generally small, indicating that the development of coordination degree of land use multi-functionalization had relatively stable spatial dependence and spatial variation direction, that was, the path locking effect was strong. In general, the overall curvature of Lisa was small, and the spatial distribution shows the pattern characteristics of highlow staggered and local agglomeration.

\section{Acknowledgements}

This work is supported by the National Natural Science Foundation of China (NO.41271189, 41671174), key research and Development Plan of Jiangsu Province 
(No. BE2018355-8) and Major Project of Chinese Academy of Engineering and Local Cooperation Consultation Research (No. JS2019ZD01-2). We thank the academic editors and anonymous reviewers for their kind suggestions and valuable comments.

\section{References}

1. FOLEY J.A. Global consequences of land use. science. 309 (5734), 570, 2005.

2. TURNER B.L, MEYER W.B., SKOLE D.L. Global land-use/land-cover change: towards an integrated study. Ambio. Stockholm. 23 (1), 91, 1994.

3. LAMBIN E.F., MEYFROIDT P. Land use transitions: Socio-ecological feedback versus socio-economic change. Land use policy. 27 (2), 108, 2010.

4. GUO L.B, GIFFORD R.M. Soil carbon stocks and land use change: a meta analysis [J]. Global Change Biology. 8 (4), 345, 2002.

5. YU Z., LU C., TIAN H., CANADELL J.G. Largely underestimated carbon emission from land use and land cover change in the conterminous US. Global Change Biology. 25, 3741, 2019.

6. LIOUBIMTSEVA ELENA A multi-scale assessment of human vulnerability to climate change in the Aral Sea basin. Environmental Earth Sciences. 73 (2), 719, 2015.

7. XU W., WU Q., LIU X., TANG A., DORE A.J. Characteristics of ammonia, acid gases, and PM2.5 for three typical land-use types in the North China Plain. Environmental Science and Pollution Research. 23 (2), 1158, 2016.

8. LIU C., HENDERSON B.H., WANG D., YANG X., PENG Z.R. A land use regression application into assessing spatial variation of intra-urban fine particulate matter (PM2.5) and nitrogen dioxide (NO2) concentrations in City of Shanghai, China. Science of The Total Environment. 565, 607, 2016.

9. BRIAN MCGILL Biodiversity: Land use matters. Nature. 520 (7545), 38, 2015.

10. LI J., LI Y., ZHANG W., YU J. Imbalanced ownership transformation and land use within an urban area: a case study of Beijing. Land Use Policy. 74 (5), 240, 2018.

11. LONG H.L., GE D.Z, W Y. Progress and prospects of the coupling research on land use transitions and rural transformation development [J]. Acta Geographica Sinica. 74 (12), 2547, 2019 [In Chinese].

12. RUDOLF DE GROOT Function-analysis and valuation as a tool to assess land use conflicts in planning for sustainable, multi-functional landscapes. Landscape \& Urban Planning. 75 (3-4), 186, 2006.

13. CAMPBELL D.J., GICHOHI H., MWANGI A., CHEGE, L. Land use conflict in Kajiado District, Kenya. Land Use Policy. 17 (4), 337, 2000.

14. ZHOU D., XU J.C., LIN Z.L. Conflict or coordination? Assessing land use multi-functionalization using production-living-ecology analysis. Science of the Total Environment. 577, 136, 2016.

15. PACIONE M. Private profit, public interest and land use planning - A conflict interpretation of residential development pressure in Glasgow's rural-urban fringe. Land Use Policy. 32 (5), 61, 2013.

16. FAN Y.T., JIN X.B., GAN L., JESSUP L.H., PIJANOWSKI B.C., YANG X.H., XIANG X.M., ZHOU Y.K. Spatial identification and dynamic analysis of land use functions reveals distinct zones of multiple functions in eastern China. Science of the Total Environment. 642, 33, 2018.

17. LIU J., JIN X.B., XU W.Y., FAN Y.T. Spatial coupling differentiation and development zoning trade-off of land space uilization efficiency in eastern China.Land Use Policy. 85, 310, 2019.

18. LIU Y.S., LI Y.H. Revitalize the world's countryside. Nature. 548 (7667), 275, 2017.

19. WANG X.L., SABINA ALKIRE. Multidimensional Poverty Measurement in China: Estimation and Policy Implications. China Rural Economy. 12, 4, 2009 [In Chinese].

20. XU J.H., LU F., SU F.L., LU Y. Spatio-temporal analysis of regional economic differences in China . Geographical research. 24 (1), 57, 2005 [In Chinese].

21. GUO Y., ZHANG C.C., KANG Y.Y. Land assessment division research on economic development in Henan province. Geographical research. 34 (12), 2320, 2015 [In Chinese].

22. VERBURG P.H., STEEG J.V.D., VELDKAMP A., WILLEMEN L. From land cover change to land function dynamics: A major challenge to improve land characterization. Journal of Environmental Management. 90 (3), 1327, 2009.

23. PENG J., CHEN X., LIU Y., LÜ H.L., HU X. Spatial identification of multifunctional landscapes and associated influencing factors in the Beijing-Tianjin-Hebei region, China. Applied Geography. 74, 170, 2016.

24. BILLS N., GROSS D. Sustaining multifunctional agricultural landscapes: comparing stakeholder perspectives in New York (US) and England (UK). Land Use Policy. 22 (4), 321, 2005.

25. ATWELL R.C., SCHULTE L.A., WESTPHAL L.M. How to build multifunctional agricultural landscapes in the U.S. Corn Belt: Add perennials and partnerships. Land Use Policy. 27 (4), 1090, 2010.

26. WANG Y., MA L., LIU Y. Progress and trend analysis of urbanization research: Visualized quantitative study based on CiteSpace and HistCite. Progress in Geography. 37 (2), 239, 2018 [In Chinese].

27. TAN K.C. Small Towns in Chinese Urbanization. Geographical Review. 76 (3), 265, 1986.

28. LAN F., DA H., WEN H., WANG Y. Spatial Structure Evolution of Urban Agglomerations and Its Driving Factors in Mainland China: From the Monocentric to the Polycentric Dimension. Sustainability. 11 (3), 610, 2019.

29. XU X., ZHAO Y., ZHANG X.L., XIA S.Y. Identifying the Impacts of Social, Economic, and Environmental Factors on Population Aging in the Yangtze River Delta Using the Geographical Detector Technique. Sustainability. 10 (5), 1528, 2018.

30. YAN H.M, LIU F., LIU J.Y., XIAO X.M., QIN Y.W. Research on Land Use Intensity and Bearing Capacity in China. Journal of Geographical Sciences. 27 (4), 387, 2017.

31. LIU Y., YANG Y., LI Y., LI J. Conversion from rural settlements and arable land under rapid urbanization in Beijing during 1985-2010. Journal of Rural Studies. 51 (1), 141, 2017.

32. JIE C. Rapid urbanization in China: A real challenge to soil protection and food security. Catena. 69 (1), 15, 2007.

33. STEINHÄUSSER R., SIEBERT R., STEINFÜHRER A., HELLMICH M. National and regional landuse conflicts in Germany from the perspective of stakeholders. Land Use Policy. 49 (12), 183, 2015. 
34. HELMING K., TSCHERNING K., KONIG B. Ex ante impact assessment of land use changes in European regions:the SENSOR approach//Helming K., Perez-Soba M., Tabbush P. Sustainablity impact assessment of land use changes.Berlin\&Heidelberg,Germany,Spriger, 2008, 77, 2008.

35. XIE G.D., ZHEN L., ZHANG C.X., DENG X.Z., HANNES J.K., KAREN T., KATHARINA H. Assessing the multifunctionalities of land use in China. Journal of Resources and Ecoloogy. 1 (4), 311, 2010.

36. NEUS MARTÍ, MICHEL PIMBERT Barter markets for the conservation of agro-ecosystem multi-functionality: the case of the chalayplasa in the Peruvian Andes. International Journal of Agricultural Sustainability. 5 (1), 51, 2007.

37. REIDSMA P., KÖNIG H., FENG S.Y., BEZLEPKINA I., NESHEIM I., BONIN M. Methods and tools for integrated assessment of land use policies on sustainable development in developing countries. Land Use Policy. 28 (3), 617, 2011.

38. WANG F., DONG Y.X. Multi-functional dynamic evaluation of land use and obstacle factor diagnosis based on grey relation projection method: Taking Guangzhou as an example. Journal of Natural Resources. 30 (10), 1698, 2015 [In CHinese].

39. SUN F.L., XU Y.Q., LIU Q.G., LIU C., HUANG A. County-scale spatial-temporal differentiation and influencing factors of land-use versatility in the BeijingTianjin poverty zone. Journal of Agricultural Engineering. 33 (15), 283, 2017 [In CHinese].

40. LIU J.L., LIU Y.S., LI Y.R. Classification and Evaluation of Spatial and Temporal Patterns of China's "productionpiving-ecologcal”Space. Acta Geographica Sinica. 72 (7), 1290, 2017 [In Chinese].

41. LI G.D., FANG C.L. Quantitative identification and analysis of urban ecological-production-living space functions. Acta Geographica Sinica. 71 (1), 49, 2016 [In Chinese].

42. XI J.C., WANG S.Z., ZHANG RUIYING. Reconstruction and Optimization of "Production-Life-Ecology" Space in Tourism and Rural Settlements - Case Study of Gogezhuang Village in Yesanpo Tourism District, Hebei Province . Journal of Natural Resources. 31 (3), 425, 2016 [In Chinese].

43. DEWI S., NOORDWIJK M.V., EKADINATA A., PFUND J.L. Protected areas within multifunctional landscapes: Squeezing out intermediate land use intensities in the tropics?. Land Use Policy. 30 (1), 38, 2013.

44. MIGUEL B., ROLAND C., CANALS LLOREN MILÀ I., LAUREN B. A Life-Cycle Approach to Characterising Environmental and Economic Impacts of Multifunctional Land-Use Systems: An Integrated Assessment in the UK. Sustainability. 2 (12), 3747, 2010.

45. HERSPERGER A.M., LANGHAMER D., DALANG T. Inventorying human-made objects: A step towards better understanding land use for multifunctional planning in a periurban Swiss landscape. Landscape and Urban Planning. 105 (3), 314, 2012.

46. WANG C., TANG N. Spatio-temporal characteristics and evolution of rural productionliving-ecological space function coupling coordination in Chongqing Municipality. Geographical Research. 37 (6), 1100, 2018 [In CHinese].

47. REY S.J., YE X. Comparative spatial dynamics of regional systems. In: Páez J et al. Progress in Spatial Analysis: Theory,Computation, and Thematic Applications. Heidelberg: Springer. 441, 2010.

48. REY S.J. Spatial analysis of regional income inequality. In: Goodchild M, Janelle D. Spatially Integrated Social Science:Examples in Best Practice. Oxford: Oxford University Press. 280, 2004.

49. LU C.X., XIE G.D., MA B.B., FENG Y. The Evolution of Multifunctional Use of Space in the Process of Regional Development in China.Resources Science. 31 (4), 531, 2009 [In Chinese].

50. HAKEN H. Advanced Synergy [M]. Beijing: Science Press. 1989 [In Chinese].

51. RUI X., LIU Y., XU F.F., WEI W.Y., ZHONG H.Z., QING X.M. Ecosystem health assessment: A comprehensive and detailed analysis of the case study in coastal metropolitan region, eastern China [J]. Ecological Indicators. 98:363376, 2019.

52. LIU Y.S., LIU Y., CHEN Y.F. Territorial multifunctionality evaluation and decision-making mechanism at county scale in China. Acta Geographica Sinica. 66 (10), 1379, 2011 [In Chinese].

53. ZHANG Y., CAO W., LIANG S., HU Y. Research on the co-evolution temporal and spatial patterns of urbanization in Yangtze River economic belt. Resources and Environment in the Yangtze Basin. 25 (5), 715, 2016 [In Chinese].

54. CAO G., BIAN X., LIU T. Comprehensive evaluation of the urbanization level in Yangtze River Delta Region: An index framework based on the population, economic structure and land use. Geographical Research. 30 (12), 2139, 2011 [In Chinese].

55. LIAO C.B. Quantitative Evaluation and Classification System for the Coordinated Development of Environment and Economy: A Case Study of the Pearl River Delta Urban Agglomeration. Tropical Geography. 19 (2), 171, 1999 [In Chinese].

56. XU L., DONG J., CHEN E. Coordination characteristics of Land and Space Utilization of Urban agglomeration in the Middle reaches of the Yangtze River based on the function of "production-living-ecological".Soil and water conservation research, 25 (2), 257, 2018 [In Chinese].

57. YE X.Y., REY S. A framework for exploratory spacetime analysis of economic data. The Annals of Regional Science. 50 (1), 315, 2013. 